\title{
Article
}

\section{Sibling interaction as a facilitator for talent development in sport}

Taylor, R.D., Collins, D., and Carson, H.J.

Available at http://clok.uclan.ac.uk/14683/

Taylor, R.D. ORCID: 0000-0001-9530-8355, Collins, D., ORCID: 0000-00027601-0454 and Carson, H.J. ORCID: 0000-0002-3785-606X (2017) Sibling interaction as a facilitator for talent development in sport. International Journal of Sports Science and Coaching, 12 (2). pp. 219-230. ISSN 17479541

It is advisable to refer to the publisher's version if you intend to cite from the work. http://dx.doi.org/10.1177/1747954117694926

For more information about UCLan's research in this area go to http://www.uclan.ac.uk/researchgroups/ and search for < name of research Group>.

For information about Research generally at UCLan please go to http://www.uclan.ac.uk/research/

All outputs in CLoK are protected by Intellectual Property Rights law, including Copyright law. Copyright, IPR and Moral Rights for the works on this site are retained by the individual authors and/or other copyright owners. Terms and conditions for use of this material are defined in the policies page.

\section{CLoK}

Central Lancashire online Knowledge www.clok.uclan.ac.uk

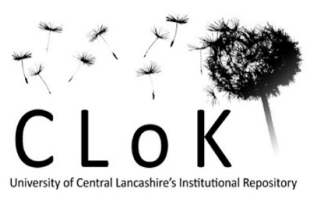




\title{
Sibling interaction as a facilitator for talent development in sport
}

\author{
Robin D Taylor, Dave Collins and Howie J Carson
}

SSAGE

\begin{abstract}
While current research has begun to address parental influences on talent development in sport, sibling interaction remains relatively under-examined. Therefore, this study aimed to explore the underpinning mechanisms through which sibling interaction impacts on talent development. Retrospective phenomenological interviews were conducted with four sets of siblings ( $N^{1} 1 / 49$ ), where at least one sibling had competed to an elite level. Findings revealed several higher order themes that impacted positively on the talented athletes' development: regularity of interaction in sport, emotional interpersonal skills, rivalry, resilience, co-operation and separation. Separation appeared as the athlete reached elite status, suggesting that these former mechanisms primarily impact during the development phase. Such findings support and extend the sibling, elite sport and talent development literature and provide valuable insight for both practitioners and academics. Importantly, coaches should consider a sibling's role as an important mechanism outside of the formal coaching structure for talent development.
\end{abstract}

Keywords

$22,22,22$

\section{Introduction}

With elite-level youth sport relying heavily on the family as a facilitating agent for children's involvement, ${ }^{1,2}$ it is surprising how little research attention has been directed towards sibling interactions in an effort to accelerate the development of sporting talent (cf. Abbott and Collins ${ }^{3}$ ). Indeed, this is in contrast with recent increasing efforts to examine parental influences (e.g. Holt et al. $^{4}$ and Lafferty and Triggs ${ }^{5}$ ). Therefore, in an effort to stimulate further inquiry and address this imbalance, Taylor and Collins ${ }^{6}$ highlighted the meaningful application of family systems theory (FST); see Bowen (ind the talent development (TD) and elite-level sporting context by exploring a number of influential subsystems within the family unit (e.g. parent-child, brother-sister, etc.). Crucially, these subsystems were revealed to create a structure within the family, with each member uniquely contributing to both the entire system and individual subsystems. ${ }^{7}$ In parallel research of the TD process, Pankhurst and Collins ${ }^{8}$ had already identified five underpinning constructs: sport specialisation and selection, practice, athlete development, junior and adult success and the stakeholders in the sport system. Accordingly, identifying holistic family influences as key stakeholders affords the possibility for a greater understanding of the entire dynamic and its influence. Increased research interest in this area should, therefore, be of interest to parents, practitioners and academics alike.

Before such understanding can be clearly interpreted, however, it is important that individual subsystems within the family unit receive sufficient exploration alongside the inherently nonlinear nature of TD, that is an explicit focus of FST against the challenges facing athletes. Central to this paper is the sibling relationship, which is often portrayed as the most pervasive and longest lasting relationship across the life course. ${ }^{9}$ According to FST, the boundaries of a subsystem can be placed on a dynamic continuum from permeable to enmeshed (cf. Minuchin ${ }^{10}$ ), indicating the need for temporal consideration when evaluating interactions during the longitudinal TD process. Full permeability

Reviewer: Damian Farrow (Victoria University, Australia)

Institute of Coaching and Performance, University of Central Lancashire, Preston, UK

Corresponding author:

Robin D Taylor, Institute of Coaching and Performance, University of Central Lancashire, 006 Greenbank Building, Preston PRI 2HE, UK.

Email:RDTaylor2@uclan.ac.uk 
could see siblings frequently seeking other family members for support (or even outside of the family system), whereas enmeshment would see siblings placing greater dependence on members of the subsystem to aid their development. ${ }^{7}$ The extent to which these boundaries change at different times, and for what reasons, may prove significant factors to overcoming the inevitable 'rocky road' to reach the top (cf. Collins and MacNamara ${ }^{11}$ ). In other words, sibling dynamics within a family support structure may facilitate the acquisition of pertinent psycho-behavioural skills, r.g. resilience and quality practice, ${ }^{12}$ essential for effecte exploitation of learning environments.

Notably, and as expressed earlier, sibling relationships have been comparatively neglected by those who focus on family influences within sport. ${ }^{13,14}$ As such, there is a distinct lack of exemplifying evidence for the impact of this dynamic relationship, let alone guidance on how this might inform effective coaching practice: almost all attention being directed towards parent-athlete relationships (e.g. Netball ${ }^{15}$ and Notting $\left(\right.$ arre $^{16}$ ). Indeed, this is emphasised by Harwood et al. ${ }^{17}$ when suggesting that 'the role of the intact family remains limited by a lack of focus on sibling influences' (p. 483), whilst Co te' and Hay ${ }^{18}$ provide further rationale for such study by suggesting that sibling relationships can impact upon the entire family when there is a talented athlete (or indeed multiple talented athletes; e.g. the Williams sisters/Murray brothers - tennis, Molinari brothers - golf, Brownlee brothers - triathlon, Klitschko brothers - boxing, Mowen sisters - volleyball, Youngs brothers - rugby and the Neville brothers - football and Neville sister Netball) involved. Furthermore, as Bloom ${ }^{19}$ suggests, talented individuals access the road to expertise early and usually within their own home. Therefore, because the sibling subsystem is essential to FST, it has the potential to impact upon TD and is worthwhile of further investigation.

\section{Sibling interactions: Possible mechanisms for a facilitative role}

Furman and Buhrmester ${ }^{20}$ exemplify how siblings can be a consistent source of companionship, help and/ or emotional support, allowing key psychosocial/ behavioural skills to be developed. Older siblings fulfil this by serving as caretakers, teachers or role models. Indeed, these views are congruent with those of Dunn, ${ }^{21}$ who identified that a common coping mechanism was to confide with a sibling rather than a friend, since siblings can provide a stronger and more trusted source of support during stressful times. ${ }^{22}$ Notably, however, Furman and Buhrmester acknowledge that this relationship is not always egalitarian and can also be asymmetrical, especially with power and status; potentially leading to rivalry. Pfouts ${ }^{23}$ discovered that such rivalry often stems from frustrated dependency needs, emotional struggles and competitive intrusion with respect to gaining acknowledgement and approval. These studies suggest that siblings often play a multifactorial role in their counterpart's lives, therefore reflecting the complex nature of TD environments.

Evidently, according to a limited number of empirical studies, these characteristics of a sibling relationship also remain active within elite sporting contexts. Greendorfer and Lewko ${ }^{24}$ identified siblings as one of the most important socialising agents with respect to sport involvement, while Richter ${ }^{25}$ highlighted that cooperation can often be a favourable characteristic of TD environments (see also $\mathrm{Co}^{\wedge} \mathrm{te}^{\prime}$ and Hay ${ }^{18}$ ). For example, by working as a cohesive unit and therefore removing the desire for siblings to seek individual rec- ognition: one sibling spotting another on the bench press in the gym. From a negative perspective, Kay ${ }^{1}$ highlighted the worries of parents who were aware of the less-talented sibling being left out, with siblings shar- ing concerns around being overshadowed. However, siblings also shared pride in their talented counterparts; thus, acting as a potential source of motivation through encouragement. As such, these findings offer possible mechanisms that could promote positive or negative TD environments.

Supporting the notion of co-operation, Trussell ${ }^{26}$ aimed to understand how organised recreational sport influences sibling relationships and interactions. She identified that sibling subsystems may breed a sense of unity, as well as affording mentor-type relationships to be developed, allowing new skills to be taught. Indeed, the practice of dyadic learning is not new to the field of sport pedagogy (e.g. verbal interaction, giving and receiving feedback and encouraging each other; ${ }^{27}$ possibly before, during or after training). These findings may, however, inform better pairings during sport participation, at least during certain times and with specifically desired outcomes, ag. a first judo class for a shy younger brother.

More recently, Davis and Meyer ${ }^{30}$ explored the psychological factors associated with on-field competition against siblings, leading to suggestions that sibling competition served as motivation to increase effort during training and competition. Referring to birth position within the subsystem, the authors proposed that this competition was often due to the younger sibling's feelings of inferiority in relation to their older, talented, sibling. This appears consistent with the wider literature that suggests rivalry often stems from the younger sibling attempting to overtake the older. ${ }^{31}$ Davis and Meyer provide further insight towards the positive role characteristics. In brief, high level 
interactions elevate emotional and instructional support, leading siblings to describe a continued closeness. As such, the combination of support and rivalry within a sporting context may be a positive mechanism for TD.

Most recent research has focused on sibling sport achievement ${ }^{13}$ and sport expertise, ${ }^{32}$ showing the reliability of emergent constructs from previous research across different sports (cf. Bloom ${ }^{19}$ ). For example, Hopwood et al.'s ${ }^{32}$ investigation shows support for the provision of emotional and instructional support to their younger sibling. Likewise, Blazo et al. ${ }^{13}$ suggested that younger siblings admire their older sibling for their achievements, which can foster a close and intensive relationship. As a cautionary note, however, Blazo et al. propose that this can cause the younger sibling to feel pressure in their pursuit of surpassing such achievement, often leading to jealousy and rivalry. ${ }^{33}$ Therefore, effective provision of TD environments must be prepared and equipped with appropriate monitoring procedures.

It is clear from the reviewed literature that, when taking a holistic view of TD, the sibling subsystem has potential for significant impact, as it is likely to be a constant and dynamic element of the environment. ${ }^{34}$ Despite providing some insight into the sibling subsystem within TD, there is little (cf. Hopwood et $a^{32} .^{32}$ focus on its impact in sport specifically. That is, how these mechanisms may have been operationalised within practice to develop the requisite skills ${ }^{12}$ for elite-level careers. To reveal how this might work, it is important to look beyond youth sport at present and instead look back from the perspective of a successful athlete: a notably missing approach from current studies; at least to the best of our knowledge. As such, this paper aimed to explore the direct impact that siblings can have on TD through their interactions. Specifically, this was explored within the elite sport context where at least one sibling was, or had recently been, involved in elite sport, focusing on their, and their siblings', perceptions towards the developmental years leading up to the achievement of elite status (i.e. their interpretation towards the sibling relationship that they believe was important to their success).

\section{Method}

By adopting a phenomenological approach it was possible to gain a rich understanding of the family culture within TD environments. Phenomenology has a tradition within qualitative research (e.g. Bernet et al. ${ }^{35}$ ) and focuses on understanding the perceived meaning of experiences as interpreted by the participant; in this case, retired elite-level athletes and their siblings. Phenomenology, therefore, lends itself well to situations that are complex, process driven and novel, ${ }^{36}$ as representative of TD. ${ }^{11}$

\section{Participants}

Participants $\left(M_{\text {age }} 1 / 444\right.$ years, $S D$ 1/4 5.01) were four purposively and conveniently sampled retired elitelevel athletes and their siblings (three dyads and one triad emerged as a result of availability). All athletes were multiple Olympians or professional athletes during their careers, from a variety of team and individual sports (see Table 1). By conducting a retrospective study it was important that participants would be able to reflect on their lived experiences. This was a deliberate criteria applied to provide a breadth of study across a range of sports.

Ethical approval was obtained through the university's ethics committee and signed informed consent provided prior to data collection.

\section{Data collection}

Individual retrospective phenomenological interviews, lasting between 40 and $60 \mathrm{~min}$, were conducted to encourage participants to share their experiences, the essential context and underpinned meaning. ${ }^{37}$ While discussions were wide ranging, the interviews broadly addressed three topics: behaviours and experiences during the TD period, feelings towards their/the athlefes development/success and the resultant impact. Thls approach sits within phenomenology since it allows the interview to take a relatively unstructured and open-ended course, with the questions designed to encourage participants to respond within context. ${ }^{38}$ It was felt that the nature of phenomenological interviews reduces potential bias in interpretation, since participants are encouraged to explain their understanding of the context/actions contained within their response; in other words, the interviewer was not leading.

\section{Data analysis}

Data were transcribed verbatim, before conducting an interpretive phenomenological analysis (IPA). Smith ${ }^{39}$ highlifit) that meaning is central to IPA and that the aim is to try to understand the content and complexity of those meanings. Therefore, it was crucial to engage in an interpretative relationship with the transcripts through sustained engagement. The corresponding author began by reading each set of transcripts to develop an in-depth and clear account while making informal notes to record their initial impression, before moving on to examine further sets of siblings on a case-by-case basis. Data were then coded inductively as individual meaning units and grouped 
Table 1. Participant profiles.

\begin{tabular}{|c|c|c|c|c|}
\hline Family & Sex & Age & Sports played & Skill level \\
\hline \multicolumn{5}{|l|}{ Family I (FI) } \\
\hline Older sibling (OS) & Male & 37 & Tennis, shinty, rugby, skiing, football & Semi-elite \\
\hline Younger sibling (YS) & Male & 36 & Tennis, shinty, skiing, football & Elite $^{\mathrm{b}}$ \\
\hline \multicolumn{5}{|l|}{ Family 2 (F2) } \\
\hline Older sibling & Male & 43 & Motor-cross, football, skeleton, basketball & Elite $^{\mathrm{b}}$ \\
\hline Younger sibling & Male & 39 & Motor-cross, football, basketball & Nonelite $^{c}$ \\
\hline \multicolumn{5}{|l|}{ Family 3 (F3) } \\
\hline Older sibling & Female & 51 & Hockey, netball, curling & Elite $^{\mathrm{b}}$ \\
\hline Middle sibling (MS) & Male & 49 & Squash, curling, badminton, rugby, football & Elite $^{\mathrm{b}}$ \\
\hline Younger sibling & Female & 47 & Hockey, netball, curling & Elite $^{b}$ \\
\hline \multicolumn{5}{|l|}{ Family 4 (F4) } \\
\hline Older sibling & Male & 46 & Football, cricket & Nonelite $^{c}$ \\
\hline Younger sibling & Male & 45 & Football, cricket, running & Elite $^{\mathrm{b}}$ \\
\hline
\end{tabular}

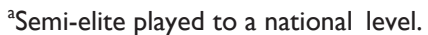

bElite participants played to an international or professional level.

${ }^{c}$ Nonelite played at a recreational level.

together to form lower and higher order themes; beginning with specific examples within the transcripts before developing more general themes. This was done by reading each transcript a number of times and annotating any interesting and significant statements in the left-hand margin. Significance was assessed based on importance rather than frequency, ${ }^{40}$ therefore not all themes apply across all participants.

Once completed with all sets of transcripts, emerging themes were then noted in the right margin. These allowed connections to be made across cases, before clustering into higher order theoretical concepts. ${ }^{41}$ To address the issue of trustworthiness and prevent the potential for misrepresenting data codes, peer debriefing took place with a second researcher. In the case of a dispute (which occurred in less than $5 \%$ of cases), alternative interpretations were presented until a plausible explanation was agreed upon. ${ }^{42}$

\section{Results}

The following section details the key themes underpinning sibling interactions during the TD process. Raw data quotations are used from exemplar participants to support and add clarity to discussion (see Table 2).

\section{Regularity of interaction in sport}

While it would be unexpected if siblings were not in regular interaction during their youth years, the following theme represents the extent of this interaction (i.e. its regularity) and domains in which it was reported. Derived from a total of 27 raw data codes, the following lower order themes emerged: competition, training and recreation. Interaction through competition was reported by all four sibling subsystems. F4OS highlighted that they 'played for the school team together and played for the town team'. Within individual sports, one sibling also explained that they would compete in the same competitions, this time outside the school setting, "Throughout the summer I would have gone to all of them [competitions] because obviously it was the school holidays, so we would play exactly the same competitions then, you know, and my family was there throughout our involvement' (F1-OS). Even when not competing, one participant explained that their siblings would be present watching them:

We would go and watch his games when he was playing and we weren't and he'd come and watch our games when he wasn't, so there was always contact there. You would see each other every day at the centre. (F3YS)

The theme of training was again reported by all four sibling subsystems. As explained, sibling interaction during training led to extra or additional practice time:

I probably played once or twice a week with my brother, he probably drove me on a bit, but also made certain things so much easier, so much dead time you know. Even if me and him were hitting balls for an hour, well then you'd hit for an hour and one side you have forty minutes getting changed getting to the place, getting out of school, and the other side getting back to it. (F1-YS)

When we were at home we' $\mathrm{d}$ be in the same place at the same time. So we used to train together, and we would 
Table 2. Themes and sub-themes with raw data codes.

\begin{tabular}{|c|c|c|}
\hline Raw data codes $(n)$ & Lower order themes & Umbrella themes \\
\hline $\begin{array}{l}\text { Played for school team and town team together (I) } \\
\text { Competing with them at same level (4) } \\
\text { Play exactly the same competitions ( } 3 \text { ) } \\
\text { Every weekend we raced (I) }\end{array}$ & Competition & $\begin{array}{l}\text { Regularity of interaction } \\
\text { in sport }\end{array}$ \\
\hline $\begin{array}{l}\text { Played once or twice a week (I) } \\
\text { Practiced quite a lot with them (4) } \\
\text { Train in the same places (I) } \\
\text { Practice outside of competition (5) }\end{array}$ & Training & \\
\hline $\begin{array}{l}\text { Take all three of us along to play (2) } \\
\text { Involved with my [siblings] at different sports (2) } \\
\text { Played together in a set area (2) } \\
\text { Played board games (I) }\end{array}$ & Recreation & \\
\hline $\begin{array}{l}\text { Always in close contact (2) } \\
\text { Became closer (2) } \\
\text { Was this unbreakable bond (3) } \\
\text { Strength of trust and bond as brothers (I) } \\
\text { Have such a lot in common (I) }\end{array}$ & Closeness & $\begin{array}{l}\text { Emotional interpersonal } \\
\text { skills }\end{array}$ \\
\hline $\begin{array}{l}\text { They all supported me (5) } \\
\text { A sounding board ( } 3 \text { ) } \\
\text { Very sort of supporting (4) } \\
\text { Was there } 100 \% \text { for me }(2) \\
\text { You would encourage each other (2) } \\
\text { I've never asked for any advice (I) } \\
\text { Wasn't a great deal of support (I) }\end{array}$ & Support & \\
\hline $\begin{array}{l}\text { We have all been there (I) } \\
\text { Knew what each of us was going through (2) }\end{array}$ & Empathy & \\
\hline Ultracompetitive (I) & Competition & Rivalry \\
\hline $\begin{array}{l}\text { Always competitive (3) } \\
\text { Obviously we were competitive (2) } \\
\text { Made it more competitive (2) } \\
\text { Don't class being competitive as a negative (I) } \\
\text { Without it we wouldn't have achieved (I) }\end{array}$ & & \\
\hline Made me even more determined (I) & Success & \\
\hline $\begin{array}{l}\text { Pissed off if they won and I didn't (I) } \\
\text { Do our best to win (I) } \\
\text { Was all about success (I) } \\
\text { Accused me of cheating (I) } \\
\text { Had a brother who was good at everything (I) }\end{array}$ & & \\
\hline $\begin{array}{l}\text { Level I was striving to get to }(2) \\
\text { Frustration now and again (2) } \\
\text { Wanted to do the same as him (I) } \\
\text { Play to win (I) }\end{array}$ & Ambition & \\
\hline $\begin{array}{l}\text { Toughened me up (I) } \\
\text { Gave me a determination ( } 2) \\
\text { Develop a bit more resilience (2) } \\
\text { Inner strength (I) }\end{array}$ & Mental process & Resilience \\
\hline $\begin{array}{l}\text { Taking the mickey out of each other (I) } \\
\text { Learnt to either take it or pack it in (I) }\end{array}$ & Behaviour & \\
\hline We would talk through it (3) & Verbal & Co-operation \\
\hline $\begin{array}{l}\text { Come and help you (I) } \\
\text { Get some feedback (I) } \\
\text { Share our experiences (I) }\end{array}$ & & \\
\hline
\end{tabular}


Table 2. Continued

\begin{tabular}{lll}
\hline Raw data codes $(n)$ & Lower order themes & Umbrella themes \\
\hline I would learn and then teach $(I)$ & Physical & \\
Build bikes together $(2)$ & & \\
He'd teach me to do things $(I)$ & Time & Separation \\
We did stuff together $(2)$ & & \\
We didn't hang out (I) & & \\
Wouldn't spend much time with him (I) & \\
Less time together (2) & Distance \\
Did a lot of it apart (3) & \\
Was not able to attend (I) & \\
He was away living in digs (I) & \\
Involve a bit more travelling (I) & \\
Quite often I would be away (I) & \\
I was boarding (I) &
\end{tabular}

go down to the centre together. Just as practice outside of competition. We did just as extra sessions. (F3-MS)

F3-YS highlighted the high degree of continuity in the interaction with her siblings across both season and off-season periods:

When we were training you were probably on the ice every other day, whether that be games or practice. Plus we'd do off ice training as well two or three times a week, we were running, doing circuit training and that would be in the off-season.

These quotations were supported by further raw data codes such as 'other weeks you'd see them the whole week and practice quite a lot with them' (F1YS) and 'I mean we did practice [together] and I think there was a respect there that we wouldn't play dirty tricks on each other' (F2-OS).

Recreation emerged as further opportunity for regular sporting interaction and was identified by two of the four sibling subsystems as an important part of their development. F4-OS explained how this recreation consistently took place within their local community:

We all played together in a set area, we used to call it 'the pen'. We used to play football there and we had a grassed area as well. Just a proper good game of football, jumpers for goalposts football.

This echoes the idea of 'deliberate play', which we turn to later. However, relating to more externally driven activity F3-MS explained how recreation with their parents and siblings led to their initial interest in the sport:

When we first started, my mother used to take all three of us along to play and my sisters used to love it and
I didn't ... I could see they liked it and maybe that was part of why I started to like it, because I could see they liked it. (F3-MS)

F3-MS summarised the importance of regular interaction with their family through recreation: 'In terms of my own development in the sport, being involved with my sisters and my parents at a range of different sports and even just growing up in that environment was invaluable to me in terms of development'.

The following themes are inherently related to these examples of regular interaction, due to the fact that they are derived from the same family system.

\section{Emotional interpersonal skills}

All participants referred to a range of interactions that encouraged an emotional connection to be made between siblings. These emotional skills, closeness, support and empathy, emerged from 30 raw data codes. One sibling identified how, although they were very different people, their sport participation facilitated closeness:

I think we have quite different personalities, but both sporty, like into sport and obviously that gives an instant attachment when we grew up together. So we were always in close contact, regular contact, you know I'd chat to him about stuff. (F1-YS)

F2-OS revealed that he felt sport had brought them closer together:

I think in some ways we became closer, because we went to race meetings together, and the underlying affection that sits there anyway exists between both brothers and that never changed, that was always 
there. I certainly think we became closer socially, we started to socialise together because of the sport.

F3-OS reflected on this relationship and explained the similarities that sport can bring out in siblings:

I actually think maybe it made us closer, because we have such a lot in common and so as a family I think we were close. I saw my sister quite a lot and we did spend a lot of time together and we were actually lucky that we do get on very well.

As well as having close relationships, all the sibling subsystems identified the levels of interactional support. F3-YS identified how they would encourage each other to train hard:

You would speak to each other and say 'what have you done today', and you would encourage each other saying 'I've only done this, or I've done this', or just encouraging each other to keep going and train probably a bitharder.

F1-YS provided insight into the continuous support they felt they received from their sibling:

Overall, my brother on me would've been a hugely hugely positive influence; like massively because he would've been interested in how I was getting along, keen to see me do well, almost at all stages, even up until now. So yes he's very sort of supportive, keen to help, has helped, a good listener to what I've been involved in.

Paradoxically, however, one sibling subsystem (F4) acknowledged a lack of support between siblings, 'I've never asked for any advice from any of the family and they have never offered any advice at all... I bet they didn't know who I was playing from week to week' (F4-YS). However, this was not recognised as negative, suggesting that it 'doesn't have to be all embracing to realise your family love and support you'. His brother (F4-OS) concurred with this, stating that 'drive to succeed and develop came from within and not from family'.

Emotional interpersonal skills also included those related to empathy, with one of the sibling subsystems emphasising its importance:

[We] probably got closer to be honest because you were there to encourage each other and also you knew what each other was going through if you came off and lost a game. You could understand each other, so I would say we probably got closer as we grew up and we were all competing. (F3-YS)
The older sibling also identified empathy and the benefit of having all siblings competing at the same level:

I think we are all very proud of each other in a way, that, I think it's nice because we all know what it was like, we all know how hard it was to get there. It's a tough road through training and competition to actually get there, so I think we know what was behind it. (F3-OS)

\section{Rivalry}

The theme of rivalry emerged from 22 raw data codes, generating three lower order themes: competition, success and ambition. This theme was discussed regularly throughout the interviews by all sibling subsystems. Competitiveness spanned both sporting and nonsporting contexts, even within family games, as F4-YS describes:

When we played football as kids we were ultra-competitive, massively so, and when we played cricket, Connect 4 or whatever it was we were really competitive and were desperate to win. But because we were really really close, we would mickey take a lot, but yes it was competitive, but we knew how far to go and it would never spiral into anything nasty. We gloat when we win, but it has never changed, even if I hadn't played football.

When competing for the same place in an elite team, F3-OS recalled:

I think it would've made it more competitive, erm, I don't know what it would have been like if one of us was in and one of us wasn't. I think that's the thing after that, that might have been difficult.

The will to succeed spurred rivalry within three of the sibling subsystems. For example, F3-MS suggested that their sibling's success gave them greater determination to succeed themselves:

We all wanted to do better than the next one and I always wanted to do better. In terms of success and measuring success I think they [siblings] probably achieved more success earlier on than I did and that made me even more determined. It used to make me pissed off sometimes. If we were in the same venue and they would win and I wouldn't win, you know. From an early early age we were competitive. (F3-MS)

However, one sibling explained the negative impact it had on their behaviour, highlighting struggles with 
their talented sibling:

I was just angry within myself. I think a lot of it came down to the, you had a brother who was good at everything and it was hard to deal with in terms of people, family. Oh [brothers' name] this, [brothers' name] that, he's brilliant and you know what it was like there are other people here you know. (F2-YS)

Another sibling recalled a particular moment where rivalry led to a fallout after beating his talented sibling during competition:

We might have had to, but not really, it was never really that close in terms of the type of stuff we were playing. It never really would've been that, you know. I can remember an instance, maybe one, where he accused me of cheating when I played him once. I might have cheated, I might not. (F1-OS)

The final lower order theme, ambition, was highlighted by two of the four sibling subsystems, although data codes were predominantly reported by the lesstalented sibling. Both siblings indicated a desire to compete at the same level:

I think he was at a level where I was striving to get to so. You're at a level I want to get to, erm, there was all positive feelings there, frustration now and again you know, that he was [competing] at a level above you, but nothing bad. (F2-YS)

I remember feeling pissed off when I actually wanted to do the same as him, when I was at university and he was better than me at it and I remember thinking then if I had done what he's done then I would be better at the time. (F1-OS)

The more talented sibling in F1 (-YS) tried to summarise one of the key differences within their development and where their ambition was evident, when he suggested 'I think I used to play to win and often I felt my brother played not to lose'.

This construct may hold importance for sibling relationships where one is achieving and one is not, as such it is worthy of consideration in both the current paper and future work.

\section{Resilience}

Two sibling subsystems highlighted eight raw data codes that underpinned the umbrella theme of resilience, comprising of two lower order themes: mental process and behaviour. An exemplar mental process was 'determination', as explained by F4-YS:

So it toughened me up definitely and it gave me a determination. It sharpened you up a little bit as well, because you were smaller, you had to do that sort of thing to survive even though it was just lads playing football.

Giving him an 'inner strength' that F4-OS regularly highlighted as a particular strength of his brother's and one that enabled his pursuit of excellence. Indeed, this was reiterated by F1-YS, who suggested that his desire to beat his sibling was influential in their approach to competition:

And then I would hit against him and then also we'd play competitively and I'd try and beat him, and probably it was all fine, and I didn't want to lose, and you develop a bit more resilience because you don't want to lose and then when you actually come to a proper match you're a bit more resilient maybe than your opponent.

Several behaviours were identified that were perceived to develop such resilience. F4-YS identified rough behaviour as being impactful:

For me it toughened me up, because they were very rough and older than me. They were up to five or six years older than me and when you are nine, it's quite old, or even seven or eight. They used to rough you around but you learnt to either take it or pack it in. (F4YS)

We would mickey take a lot, but yes it was competitive, but we knew how far to go and it would never spiral into anything nasty. We gloat when we win, but it has never changed, even if I hadn't played football. (F4-YS)

\section{Co-operation}

The theme of co-operation emerged from 12 raw data codes that were organised into two lower order themes: verbal and physical. Verbal co-operation was identified by three of the sibling subsystems and was exemplified in both training and home environments:

I might ask my big sister's opinion and she would stand up at the other end, and I would say I had a particular problem with a shot, and by throwing it differently, and I'd get some feedback from her, and vice-versa, and the same with my little sister, and we would continue to do that as a family. (F3-MS) 
We get the salt and pepper; we were playing this shot at the weekend. And we had one shot here, and we would talk through it. And we did that as a family. We'd sit down, and there was nothing really, kind of hidden about it. (F3-MS)

You know we were such a small school who overachieved, you know getting to national school finals, 'where the hell is that', and the same with the club. So we [the siblings] would've talked through how we were tactically going to play our team, you know, who was going to play who. (F1-YS)

Physical co-operation was also discussed by two of the sibling subsystems. F2-YS talked about co-operative behaviours in the build up to competition:

We'd discuss it, build your bikes together and yes, because we'd go training together, practicing, he'd teach me to do things, or you only had to watch to learn, so yes it was great support, it was all good. I think he was at a level where I was striving to get to.

F2-OS agreed, suggesting that this aided his development as a talented athlete:

It was about the preparation for me, so the beginning of the week would be about preparing and we always generally did that together. We would learn together, or I would learn and then I'd teach him just because I was four years older, you know I was at a different stage of my education. That to me was where we spent a lot of time together, we did it together.

This physical co-operation was reflected by F3-YS when discussing their training routine:

We would train in the same places. At that stage [sisters' name] and I were playing on the same team, so we used to often do a lot of our training, gym stuff and out running together and, when it came to on ice stuff we always did it together.

\section{Separation}

Finally, separation was identified by all sibling subsystems and produced 12 raw data codes that were split into two lower order themes: time and distance. Separation was in fact counter to the idea of regular interaction, emphasising a temporal aspect of the sibling mechanism within the TD process The lower order theme of time represented a reduction of the time spent training together as they developed as athletes:

There was a period of time when I wouldn't spend much time with my sisters, maybe only see them at weekends at competitions, as opposed to living in the same house, so there was less interaction as development took place. (F3-MS)

We did some off ice type of training together, but we also did a lot of it apart, she had moved away at the time so often did her training at lunchtimes around work. So there was some separation there. (F3-YS)

F2-OS specifically described how training would lead to separation:

It [training] put a lot of pressure on. Very much to the point where I was not able to attend a lot of family functions because I was training and if I did attend and turn up I would be tired and grumpy.

The second lower order theme of distance was highlighted through F1-YS's comment that development led to increased travelling distances for training and competitions:

I then started to miss significantly more school than I ever had done. When I was in primary school I literally don't remember missing any school, and then I started getting selected for a bit more and then that involved a bit more travelling, as I was going to tournaments, selections or training camps and so I was missing like Friday after Friday.

F4-OS reflected on this separation when recalling that his brother 'moved out of the home, he was away living in digs for four or five days, say four days a week. A little bit later on' as they developed.

\section{Discussion}

This study aimed to explore the impact of sibling interaction on the TD process. Due to the nature of the sibling relationship, its longevity and its impact on individual subsystems, defining a specific time frame for TD would prove complex. Several themes identified support previous research addressing sibling subsystems, namely regularity of interaction in sport, emotional interpersonal skills and co-operation. ${ }^{13,26,30,32,43}$ Indeed, current sibling literature highlights the benefits of emotional and instructional support between siblings ${ }^{30,32}$ which were heightened through regular interaction of the sibling subsystem in this study, often within the family system. This indicates, 
therefore, growing support within the field and rationale for focusing on such a pervasive relationship. Most interestingly, however, we identified additional influential facilitators: rivalry, resilience and separation. All of these add important depth to the social dimension of the biopsychosocial perspective of TD, once again highlighting the crucially multifaceted considerations towards understanding the complex, dynamic and nonlinear process. ${ }^{44}$ As such, it appears that, in contrast to Ericsson et al.' $\mathrm{s}^{45}$ linear deliberate practice framework, Collins and MacNamara's ${ }^{11}$ rocky road idea and Abbott and Collins, ${ }^{3}$ regard for nonlinearity during $\mathrm{TD}$, provides a more parsimonious explanation to these data. Interestingly, the levels of competitiveness, achievement orientation and adult involvement suggest that these activities were less related to deliberate play than to self-organised deliberate practice.

Rather than TD systems attempting to reduce the exposure and impact of stressors/challenges to the athlete, data suggest that experiencing positive challenge (or trauma) along the TD pathway can in fact benefit those seeking expertise. Indeed, Collins et al. ${ }^{46}$ identified that 'super champions' (i.e. a minimum of 50 international caps/five international medals) progressed from these challenges more so than 'almosts' (i.e. those who nearly made it but only achieved international junior success), through key psychological characteristics they brought to, and developed as a result of, the challenges, e.g. resilience, competitiveness and social skills. ${ }^{12}$ As such, rivalry between siblings can provide adaptive and developmental purposes ${ }^{47}$ leading to outcomes that can facilitate TD. Indeed, this finding supports Davis and Meyer's ${ }^{30}$ discovery that this rivalry can lead to increased motivation to train harder, therefore allowing the potential for improved performance.

Alongside this, the importance of resilience during TD is highlighted by Sarkar and Fletcher ${ }^{48}$ who suggest that positive responses to challenging and/or pressurised environments can lead to the realisation of optimal sport performance. Accordingly, we suggest that the sibling subsystems explored in this study facilitated the development of resilience, encouraged competitiveness and independence through rivalry and fostered regular interaction with others (i.e. sporting peers, but nonfamily members) involved in sport. In addition to this increasing independence, these data also highlight the role siblings can offer as a coping mechanism for potential trauma in sport. Specifically, co-operation was reported when athletes were looking to alter or address performance underachievement and emotional interpersonal skills were discussed as critical following deselection or poor performance.

Supporting a holistic perspective as explained by FST (cf. Taylor and Collins ${ }^{6}$ ), these findings add veracity to the need for sibling consideration within TD environments. Indeed, data from this study highlight the facilitative potential of siblings to foster important characteristics (co-operation, emotional interpersonal skills and rivalry) that may not otherwise be developed through, for example, parents. Of particular interest is the noted change in the subsystem boundary as the athletes progressed closer towards expertise (i.e. separation). As such, becoming more permeable reflecting the physical distance between siblings and time spent together - inevitably meant that athletes would seek support from outside of this specific subsystem (e.g. coaches, parents, sports organisations, fellow athletes). Accordingly, FST needs to be applied across the development pathway if we are to better understand this important dynamic. The application of FST allows for a greater insight into the temporal nature of the TD process, reflected by the changing requirements of the athlete in relation to sibling and the wider family involvement.

From a practical perspective, there are important benefits to be gained from weighing up the pros and cons of how and when sibling intervention might be encouraged within a coaching environment. Crucially, we suggest the need to consider the coach's and/or the TD environment's aims alongside the athlete's needs (both generic and specific) before making a decision as to the benefit of sibling intervention. ${ }^{28}$ For example, pairing siblings up who are particularly co-operative during technical development, or putting particularly competitive siblings on opposing sides in small games might be an appropriate course of action. Siblings are still just one part of the holistic and complex coaching environment, and clearly not all siblings will have such a positive influence. Therefore, it would be wrong to propose that the sibling will be key to TD, as such intervention may have a negative impact. Fortunately, talent pathways are beginning to move away from the concept of 'if $\mathrm{X}$ then $\mathrm{Y}$ ', and therefore professional judgement and decision making is key when considering the utilisation of siblings. ${ }^{28}$

Despite these extended insights, however, it must be acknowledged that this study was not without limitation. For example, there was a distinct lack of sisters included within the sibling subsystems examined - only one of the four included female siblings. Likewise, in two of the sibling subsystems not all siblings were interviewed due to access issues. Inclusion of all and different gendered siblings in future research may yield a more holistic understanding of sibling's role within TD. Additionally, retrospective interviews rely on the memories of participants and can therefore be criticised for their subjectivity, highlighting their requirement for reliable and engaged informants for data to be rich and informative. ${ }^{49}$ Arguably from a phenomenological 
approach, however, issues of memory failure are marginalised due to the assumption that participants are providing their account of the most important elements of their own experience. Forgotten elements may, therefore, be assumed to be unimportant, or unmemorable, towards the experience. ${ }^{50}$ Nevertheless, future understanding would benefit from longitudinal tracking of junior elite athletes to explore the prominence of relationships at various points (e.g. pre-, mid- and postseason).

\section{Conclusion}

This study has outlined, and shown support towards, several mechanisms for how siblings can facilitate positive progression during the TD process, namely through regularity of interaction in sport, emotional interpersonal skills (closeness, support and empathy) and co-operation. We extend these mechanisms by highlighting that rivalry between siblings can positively impact upon TD and that siblings can contribute to the development of resilience -a fundamental psychological characteristic that can assist athletes to cope with highlevel challenge. ${ }^{51}$ It is important to also note the nonlinear role of the sibling subsystem, as reflected by the theme of separation as expertise developed, therefore reducing the facilitative role siblings can play in TD.

Accordingly, coaching practice should consider this relationship alongside the more coveted role of parents, as instrumental during the TD process. Finally, we suggest the need for careful planning both within and outside of the sporting environment and across different timescales to ensure an optimum developmental effect (cf. Abraham and Collins ${ }^{52}$ ) as well as greater utilisation of FST principles in future TD research.

\section{Declaration of Conflicting Interests}

The author(s) declared no potential conflicts of interest with respect to the research, authorship, and/or publication of this article.

\section{Funding}

The author(s) received no financial support for the research, authorship, and/or publication of this article.

\section{References}

1. Kay T. Sporting excellence: a family affair? Eur Phys Educ Rev 2000; 6: 151-169.

2. Pankhurst A, Collins D and Macnamara A. Talent development: linking the stakeholders to the process. J Sports Sci 2013; 31:370-380.

3. Abbott A and Collins D. Eliminating the dichotomy between theory and practice in talent identification and development: considering the role of psychology. J Sports Sci 2004; 22: 395-408.
4. Holt NL, Tamminen KA, Black DE, et al. Youth sport parenting styles and practices. J Sport Exerc Psychol 2009; 31:37-59.

5. Lafferty ME and Triggs C. The working with parents in sport model (WWPS-model): a practical guide for practitioners working with parents of elite young performers. J Sport Psychol Action 2014; 5: 117-128.

6. Taylor RD and Collins D. Reviewing the family as a stakeholder in talent development: is it undervalued? Quest 2015; 67: 330-343.

7. Bowen M. Family therapy in clinical practice. New York: Jason Aronson, 1978.

8. Pankhurst A and Collins D. Talent identification and development: the need for coherence between research, system, and process. Quest 2013; 65: 83-97.

9. Rittenour CE, Myers SA and Brann M. Commitment and emotional closeness in the sibling relationship. Southern Commun J 2007; 72: 169-183.

10. Minuchin S. Families and family therapy. Cambridge, MA: Harvard University Press, 1974.

11. Collins D and MacNamara A. The rocky road to the top: why talent needs trauma. Sports Med 2012; 42: 907-914.

12. Macnamara A. Psychological characteristics of developing excellence. In: Collins D, Button A and Richards $\mathrm{H}$ (eds) Performance psychology: a practitioner's guide. Philadelphia, PA: Elsevier, 2011, pp.47-64.

13. Blazo JA, Czech DR, Carson S, et al. A qualitative investigation of the sibling sport achievement experience. Sport Psychol 2014; 28: 36-47.

14. Partridge J, Brustad R and Bakes Stellino M. Social influence in sport. Adv Sport Psychol 2008; 3: 269-291.

15. Netball E. Parent, teacher and club coach information booklet, 2015.

16. Nottinghamshire S. For parents, 2015

17. Harwood CG, Douglas JP and Minniti AM. Talent development: the role of the family. In: Murphy S (ed.) The Oxford handbook of sport and performance psychology. Oxford: Oxford University Press, 2012, pp.476492.

18. Co te' J and Hay J. Family influence on youth sport performance and participation. In: Silva JM and Stevens D (eds) Psychological foundations of sport. 2nd ed. Boston, MA: Allyn and Bacon, 2002, pp.503-519.

19. Bloom BS. Developing talent in young people. New York: Ballantine, 1985.

20. Furman W and Buhrmester D. Children's perceptions of the personal relationships in their social networks. Dev Psychol 1985; 21: 1016-1024.

21. Dunn J. Sisters and brothers: current issues in development research. In: Boer F and Dunn J (eds) Children's sibling relationships: developmental and clinical issues. Hillsdale, NJ: Erlbaum, 1992, pp.1-18.

22. McHale SM, Updegraff KA and Whiteman SD. Sibling relationships and influences in childhood and adolescence. J Marriage Fam 2012; 74:913-930.

23. Pfouts JH. The sibling relationship: a forgotten dimension. Soc Work 1976; 21: 200-204.

24. Greendorfer SL and Lewko JH. Role of family members in sport socialization of children. Res Quart 1978; 49: 146-152. 
25. Richter M. The case study of a family of three elite swimmers. Ontario: Brock University, 1997.

26. Trussell D. Contradictory aspects of organized youth sport: challenging and fostering sibling relationships and participation experiences. Youth Soc 2014; 46: 801818.

27. Darnis F and Lafont L. Cooperative learning and dyadic interactions: two modes of knowledge construction in socio-constructivist settings for team-sport teaching. Phys Educ Sport Pedagogy 2015; 20: 459-473.

28. Martindale A and Collins D. Professional judgement and decision making: the role of intention for impact. Sport Psychol 2005; 19:303-317.

29. Collins D, Burke V, Martindale A, et al. The illusion of competency versus the desirability of expertise: seeking a common standard for support professions in sport. Sports Med 2015; 45: 1-7.

30. Davis NW and Meyer BB. When sibling becomes competitor: a qualitative investigation of same-sex sibling competition in elite sport. J Appl Sport Psychol 2008; 20: 220-235.

31. Haggan P. Family resilience through sports: the family as a team. J Individ Psychol 2002; 58: 279-289.

32. Hopwood MJ, Farrow D, MacMahon C, et al. Sibling dynamics and sport expertise. Scand J Med Sci Sports 2015;25:724-733.

33. Macnamara A and Collins D. Profiling, exploiting, and countering psychological characteristics in talent identification and development. Sport Psychol 2015; 29: 73-81.

34. Whiteman SD, McHale SM and Crouter AC. Competing processes of sibling influence: observational learning and sibling deidentification. Soc Dev 2007; 16: 642-661.

35. Bernet R, Kern I and Marbach E. An introduction to Husserlian phenomenology. Evanston, IL: Northwestern University Press, 1993.

36. Smith JA and Osborn M. Interpretive phenomenological analysis. In: Smith JA (ed.) Qualitative psychology: a practical guide to research methods. London: Sage, 2003, pp.51-80.

37. King $\mathrm{N}$ and Horrocks $\mathrm{C}$. Interviews in qualitative research. London: Sage Publications, 2010.

38. Englander M. The interview: data collection in descriptive phenomenological human scientific research. J Phenomenol Psychol 2012; 43: 13-35.
39. Smith JA. Evaluating the contribution of interpretative phenomenological analysis. Health Psychol Rev 2011; 5: 9-27.

40. Krane V, Andersen MB and Strean WB. Issues of qualitative research methods and presentations. J Sport Exerc Psychol 1997; 19: 213-218.

41. Smith JA and Eatough V. Interpretative phenomenological analysis. In: Breakwell G, Fife-Schaw C, Hammond S, et al. (eds) Research methods in psychology. 3rd ed. London: Sage, 2006.

42. Sparkes A. Validity in qualitative inquiry and problems of criteria: implications for sport psychology. Sport Psychol 1998; 12: 363-386.

43. Co'te' J. The influence of the family in the development of talent in sport. Sport Psychol 1999; 13: 395-417.

44. Abbott A, Button C, Pepping GJ, et al. Unnatural selection: talent identification and development in sport. Nonlinear Dyn Psychol Life Sci 2005; 9: 61-88.

45. Ericsson KA, Krampe RT and Tesch-Ro“ mer C. The role of deliberate practice in the acquisition of expert performance. Psychol Rev 1993; 100:363-406.

46. Collins D, Macnamara A and McCarthy N. Super champions, champions and almosts: important differences and commonalities on the rocky road. Front Psychol 2016; 6

47. Edward J. Sibling discord: a force for growth and conflict. Clin Soc Work J 2013; 41: 77-83.

48. Sarkar M and Fletcher D. Psychological resilience in sport performers: a review of stressors and protective factors. J Sports Sci 2014; 32: 1419-1434.

49. Singer JD and Willett JB. Survival analysis. In: Weiner IB and Velicer WF (eds) Handbook of psychology: research methods in psychology. 2nd ed. Hoboken, NJ: John Wiley and Sons Inc., 2003, pp.555-580.

50. Moran D. Introduction to phenomenology. Abingdon: Routledge, 2000.

51. Macnamara A, Button A and Collins D. The role of psychological characteristics in facilitating the pathway to elite performance. Part 1: identifying mental skills and behaviors. Sport Psychol 2010; 24: 52-73.

52. Abraham A and Collins D. Taking the next step: ways forward for coaching science. Quest 2011; 63: 366-384. 